\title{
Impact of geometrical parameters of micro-textured DLC on tribological properties under dry sliding friction
}

\author{
Tetsuhide Shimizu ${ }^{1, *}$, Hironori $\operatorname{Kan}^{1}$, Hamza Messaoudi ${ }^{2}$, Frank Vollertsen ${ }^{2,3}$, and Ming Yang ${ }^{1}$ \\ ${ }^{1}$ Division of Mechanical Engineering Systems, Tokyo Metropolitan University, Tokyo, Japan \\ 2 BIAS - Bremer Institut für angewandte Strahltechnik, Bremen, Germany \\ ${ }^{3}$ Faculty of Production Engineering-Mechanical Engineering \& Process Engineering, University of Bremen, Bremen, Germany
}

Received: 28 January 2019 / Accepted: 20 May 2019

\begin{abstract}
To achieve a stable and high wear resistive functional surface under dry sliding friction, the present study proposes micro-textured diamond-like carbon coatings fabricated by ionized physical vapor deposition (I-PVD) using metallic masks. To clarify the suitable geometrical design under dry sliding friction, geometrical quantities of textured array patterns are varied by using metallic masks with different circular hole array patterns fabricated by picosecond pulsed laser processing. The effect of texturing on friction and wear properties is evaluated by ball-on-disk type friction tests for the condition of a constant DLC-coverage per unit area. Thereby, textured DLC pattern with diameters of $50 \mu \mathrm{m}, 100 \mu \mathrm{m}$, and $150 \mu \mathrm{m}$ are applied. Within the first 10000 laps stable and lower coefficient of friction is obtained with the smallest diameters of $50 \mu m$. However, at further rotation of more than 40000 laps, the wear of the smaller diameters becomes more pronounced due to the increase of stress concentration at the edge of the structure. Based on these findings, geometrical design of microtextured DLC coating is discussed with regard to the suppression of three-body plowing and the prevention of stress concentration.
\end{abstract}

Keywords: Surface texturing / DLC / dry sliding friction / picosecond pulsed laser processing

\section{Introduction}

With the growing awareness of environmental issues, the efforts toward a lubricant-free metal forming are intensifying [1]. Since the predominant tribological factors in the case of the dry sliding friction are adhesion and deformation that result from the direct interaction of surface asperity peaks in contact with each other, the mechanical properties and the geometry of the surface asperities directly affect the friction and wear behavior [2]. In particular, under the plastic deformation of the work materials, as it is the case within a metal forming operation, wear debris of various sizes are generated and the trapped particles at the interface induce a three-body plowing behavior, which significantly increases the friction and its large deviations [3].

As a basic concept to suppress the influence of the threebody plowing caused by generated wear particles, the authors focused on a theoretical model of scale effect of the three body deformation $[4,5]$. It is supposed that wear particles at the edge

\footnotetext{
* e-mail: simizu-tetuhide@tmu.ac.jp
}

of an apparent contact area can detach from the surface if these have diameters twice as high than the width of the contact area. In contrast, particles at the center of the contact region are likely to be trapped and plough the contact surface. Thus, a down scaling of the apparent contact area can help in reducing the three-body plowing effect. For this purpose, functionalized surfaces are required.

To realize stable dry friction conditions, the authors proposed an application of surface texturing with micro structured diamond like carbon (DLC) coatings to decrease the apparent contact area during sliding [6]. In previous works, micro-textured array patterns, which were fabricated by using metallic wire meshes, have demonstrated low and stable friction coefficients under dry friction and also in application to sheet bending process [6,7]. Thereby, it was noticed that it is essential to consider the ejection of wear particles from the contact interface as a key factor in the design of suitable surface texturing. This was traced back to the crucial effect of wear debris generation and its entrapment at the interface. However, the influence of the texture dimensions under dry sliding friction on the tribological properties has not been discussed in detail for the representative contact state in metal forming. 


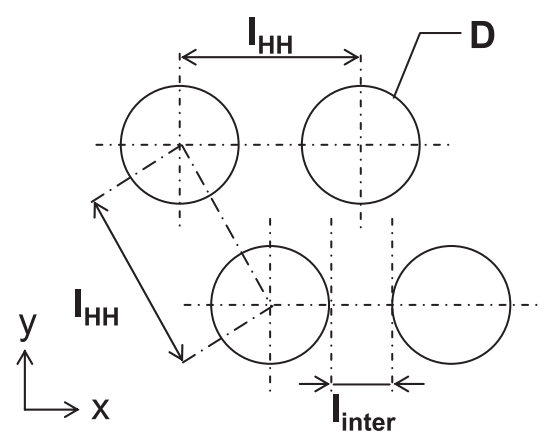

mask parameters:

$\begin{array}{lr}D & \text { hole diameter } \\ \mathrm{I}_{\mathrm{HH}} & \text { hole-to-hole distance } \\ \mathrm{I}_{\text {inter }} & \text { interspace distance }\end{array}$

material

1.4301

thickness

$10 \mu \mathrm{m}$

texturing area

$8 \mathrm{~mm} \times 8 \mathrm{~mm}$

\begin{tabular}{|llll|}
\hline & $\mathrm{D}[\mu \mathrm{m}]$ & $\mathrm{I}_{\mathrm{HH}}[\mu \mathrm{m}]$ & $\mathrm{I}_{\text {inter }}[\mu \mathrm{m}]$ \\
\hline mask type 1 & 10 & 40 & 30 \\
\hline mask type 2 & 50 & $65,80,100$ & $15,30,50$ \\
\hline mask type 3 & 100 & 130,150 & 30,50 \\
\hline Mask type 4 & 150 & 225 & 75 \\
\hline
\end{tabular}

Messaoudi 2018

BIAS ID 180068

Fig. 1. Schematic illustration of the texturing parameters as well the applied mask configurations.

The present study performed a systematic approach to vary the geometrical conditions of textured DLC coatings. Therefore, metallic masks consisting of different circular hole arrays were fabricated using picosecond laser processing. Within a suitable process window, the material removal with these ultrashort laser pulses takes place with a minimized thermal impact and is nearly distortion free. Thus, a flexible and high-precise machining can be ensured [8]. Based on the comparison of tribological properties between different texture diameters of $D=10-150 \mu \mathrm{m}$, and its interspace distance of $l_{\text {inter }}=15-75 \mu \mathrm{m}$, the role of those geometrical parameters resulting in friction and wear properties are discussed in view of ejection of wear debris and stress concentration at DLC texture units.

\section{Experimental}

\subsection{Picosecond laser fabrication of metallic masks}

To ensure a precise and multi-design DLC-deposition procedure, the manufacture of the metallic masks was provided using ultrashort pulsed laser machining. Therefore, a picosecond laser system (TruMicro 5050 from Trumpf GmbH) was used. It operates at a wavelength of $1030 \mathrm{~nm}$ in its fundamental Gaussian mode and delivers an average maximum power of $50 \mathrm{~W}$ at $200 \mathrm{kHz}$. It produces pulse widths of $<10 \mathrm{ps}$ and maximum pulse energy of $250 \mu \mathrm{J}$. The collimated laser beam is first expanded and then coupled into a frequency conversion system (Xiton box from Xiton $\mathrm{GmbH}$ ), which allows the second harmonic generation (wavelength of $515 \mathrm{~nm}$ ) in a separated optical path. Thereby, the maximum average power is about $33 \mathrm{~W}$ and the maximum pulse energy is $150 \mu \mathrm{J}$. Depending on the used wavelength, the collimated beam is coupled into one of two programmable galvanometer scanners (HurriScan 14 from ScanLab), which enable process speeds up to $12 \mathrm{~m} / \mathrm{s}$.
The orthogonal arrangement of the scanner mirrors directs the beam down toward the workpiece using an F-Theta lens (160 mm focal length). This enables both a large scan fields $(100 \mathrm{~mm} \times 100 \mathrm{~mm})$ and small focused laser spot sizes ( $48 \mu \mathrm{m}$ and $24 \mu \mathrm{m}$, for $1030 \mathrm{~nm}$ and $515 \mathrm{~nm}$, respectively) at perpendicular incidence of the laser beam. In addition, the workpiece is mounted on a $z$-axis to ensure the adjustment of the focal plane.

In this work the manufacture of the metallic masks was applied on $10 \mu \mathrm{m}$ thin stainless steel foils over an area of $8 \mathrm{~mm} \times 8 \mathrm{~mm}$. Thereby, the texturing was based on the drilling of circular micro holes having diameters $D$ between $10 \mu \mathrm{m}$ and $150 \mu \mathrm{m}$. Thereby, it has to be mentioned that the targeted diameters were realized at the laser exit side. Moreover, the interspace distance between the holes was varied between $15 \mu \mathrm{m}$ and $75 \mu \mathrm{m}$ in order to realize different DLC-coverage during the deposition procedure. The different mask configurations realized are illustrated in Figure 1.

A detailed investigation was performed to identify the influence of different process parameters on the resulting hole properties. With respect to the targeted configurations suitable laser parameters (wavelength $\lambda$, pulse energy $E_{\mathrm{p}}$, pulse repetition rate $f_{\text {rep }}$, number of pulses $n_{\mathrm{p}}$, drilling time per hole $t_{\text {hole }}$ and focal position $\Delta z$ ) were selected, as illustrated in Table 1. The characterization of the realized metallic masks at the laser exit side was performed using optical microscopy records, from which the hole diameters $D$, the hole-to-hole distance $l_{\mathrm{HH}}$ and the interspace distance $l_{\text {inter }}$ were measured.

\subsection{Ionized physical vapor deposition of DLC films}

Depositions were performed in an ionized physical vapored deposition (I-PVD) system (NPS-330S from Nanotec Corp.) 
Table 1. Applied laser parameters for the texturing of the different mask configurations.

\begin{tabular}{lllllll}
\hline $\begin{array}{l}D \\
(\mu \mathrm{m})\end{array}$ & $\begin{array}{l}\lambda \\
(\mathrm{nm})\end{array}$ & $\begin{array}{l}E_{\mathrm{p}} \\
(\mu \mathrm{J})\end{array}$ & $\begin{array}{l}f_{\mathrm{rep}} \\
(\mathrm{kHz})\end{array}$ & $\begin{array}{l}n_{\mathrm{p}} \\
(-)\end{array}$ & $\begin{array}{l}t_{\mathrm{hole}} \\
(\mathrm{s})\end{array}$ & $\begin{array}{l}\Delta z \\
(\mathrm{~mm})\end{array}$ \\
\hline 10 & 515 & 7.5 & 10 & 800 & 0.08 & 0 \\
50 & 1030 & 37.5 & 10 & 600 & 0.06 & 0 \\
100 & 1030 & 112.5 & 2 & 700 & 0.35 & +2 \\
150 & 1030 & 137.5 & 2 & 900 & 0.45 & +6 \\
\hline
\end{tabular}

Table 2. Conditions of DLC deposition by I-PVD process.

\begin{tabular}{ll}
\hline Pre-treatment of substrate & $\mathrm{Ar}^{+}$bombard \\
& $\mathrm{DC}-1 \mathrm{kV}$ for $30 \mathrm{~min}$ \\
\hline Gas species & $\mathrm{C}_{6} \mathrm{H}_{6}$ \\
Gas flow rate $(\mathrm{sccm})$ & 0.75 \\
Gas pressure $(\mathrm{Pa})$ & $2.5 \times 10^{-2}$ \\
Bias voltage $(\mathrm{kV})$ & -1 \\
Filament current $(\mathrm{A})$ & 30 \\
Temperature $\left({ }^{\circ} \mathrm{C}\right)$ & 250 \\
Deposition time $(\mathrm{h})$ & 2 \\
\hline
\end{tabular}

with a usable coating volume with a size of $\phi 150 \mathrm{~mm} \times 150$ $\mathrm{mm}$. In this system, the direct current ion source, composed of a tantalum (Ta) filament and anode electrodes, was installed to ionize the benzene $\left(\mathrm{C}_{6} \mathrm{H}_{6}\right)$ gas. Bulk specimens of sintered tungsten carbide-cobalt (WC-Co) hard alloy, JIS: V20, with a size of $14 \mathrm{~mm} \times 14 \mathrm{~mm}$ and a thickness of $5 \mathrm{~mm}$ were used as the substrate material. Prior to the deposition, the WC-Co substrates were mirror polished, cleaned sequentially in acetone and ethanol, and mounted on a table with fixing jigs. Starting with a base pressure of $<5 \times 10^{-3} \mathrm{~Pa}$, argon (Ar) gas of $10 \mathrm{sccm}$ was introduced to initiate an Ar plasma and remove the adsorption layers on the substrates by plasma etching process. The pre-treatment was performed using a DCvoltage of $-1 \mathrm{kV}$ for $30 \mathrm{~min}$. Subsequently, the DLC deposition was carried out in a $\mathrm{C}_{6} \mathrm{H}_{6}$ atmosphere at $250^{\circ} \mathrm{C}$. The $\mathrm{C}_{6} \mathrm{H}_{6}$ flow was set to $0.75 \mathrm{sccm}$ to maintain a total pressure of $2.5 \times 10^{-2} \mathrm{~Pa}$. Throughout the deposition, the substrate bias voltage was maintained at $-1 \mathrm{kV}$. The conditions of the complete process are summarized in Table 2.

\subsection{Tribological evaluations}

To characterize the basic tribological properties of the fabricated non-textured and micro-textured DLC films under dry sliding conditions, ball-on-disk type tribology tests were carried out with a commercial tribometer (TRIBOMETER, CSM Instruments). A constant normal force of $5 \mathrm{~N}$, which corresponds to an initial Hertzian mean contact pressure of about $1.2 \mathrm{GPa}$ and elastic contact diameter of approx. $110 \mu \mathrm{m}$, was applied for the all testing samples. This contact pressure is equivalent to that

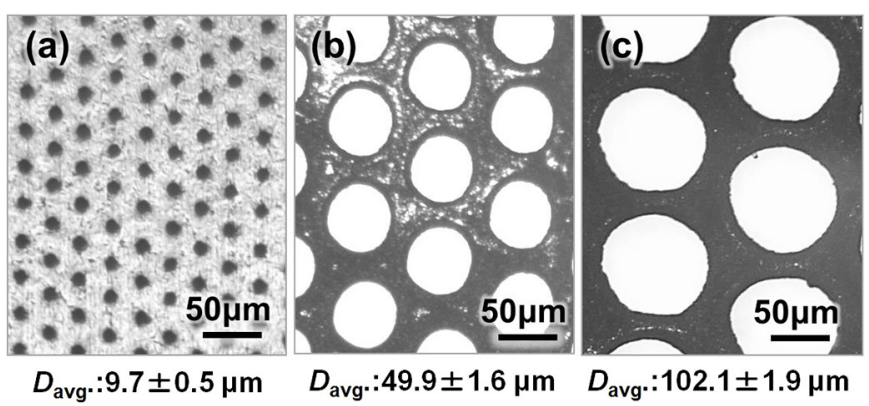

Fig. 2. Optical microscopic images of picosecond laser processed metallic masks with diameters $D$ of $10 \mu \mathrm{m}$ (a), $50 \mu \mathrm{m}$ (b) and $100 \mu \mathrm{m}(\mathrm{c})$ and a constant interspace distance linter $l_{\text {inter }}$ of $30 \mu \mathrm{m} .{ }^{*} D_{\text {avg }}$ : averaged diameter.

generally assumed in the severe contact state in metal forming, such as ironing or forging process. As a counterpart, bearing steel balls (JIS: SUJ2) and alumina $\left(\mathrm{Al}_{2} \mathrm{O}_{3}\right)$ balls with a diameter of $6 \mathrm{~mm}$ was used. In particular, alumina ball was used to evaluate the wear resistivity of the micro-textured DLC, so that wear of the ball can be minimized. The tests were performed under unlubricated condition and with a linear speed of $42 \mathrm{~mm} / \mathrm{s}$ at room temperature in ambient air. Wear tracks of the substrates and sliding balls were analyzed by optical microscopy and scanning electron microscopy (SEM). In addition, the chemical composition at the contact surface was analyzed by energy dispersive X-ray spectroscopy (EDS).

\section{Results and discussion}

\subsection{Fabrication of micro-textured DLC films by using laser manufactured metallic masks}

The first step in this work was the manufacture of the metallic masks following the design required for the subsequent DLC-deposition. Figure 2 shows exemplarily selected microscopic images of metallic masks that have a constant interspace distance $l_{\text {inter }}$. The images show that the laser machining enables a high-dimensional accuracy as well as a high reproducibility with standard deviations less than $5 \%$.

With the micro-perforated metallic masks, a microtexturing of thin DLC films was realized during the deposition process. Figure 3 shows examples of the resulting DLC coatings. The patterning was based on circular DLC islands that have diameters of approximately $D=10,50$ and $100 \mu \mathrm{m}$ and a constant interspace distance of $l_{\text {inter }}=30 \mu \mathrm{m}$. Other examples that show DLC structures with a constant island diameter of $50 \mu \mathrm{m}$ and a varied interspace distance from $l_{\text {inter }}=15,30$ and $50 \mu \mathrm{m}$, are depicted in Figure 4. For all patterns, the thickness of the DLC coating was $\approx 300-400 \mathrm{~nm}$. From the related surface profiles (see Figs. 3 and 4), which were measured using a 3D surface profiler, it can be seen that the circular island structure patterns are characterized by sharp edges and a high dimensional accuracy. Therefore, the suitability of picosecond laser machining for the precise and flexible 

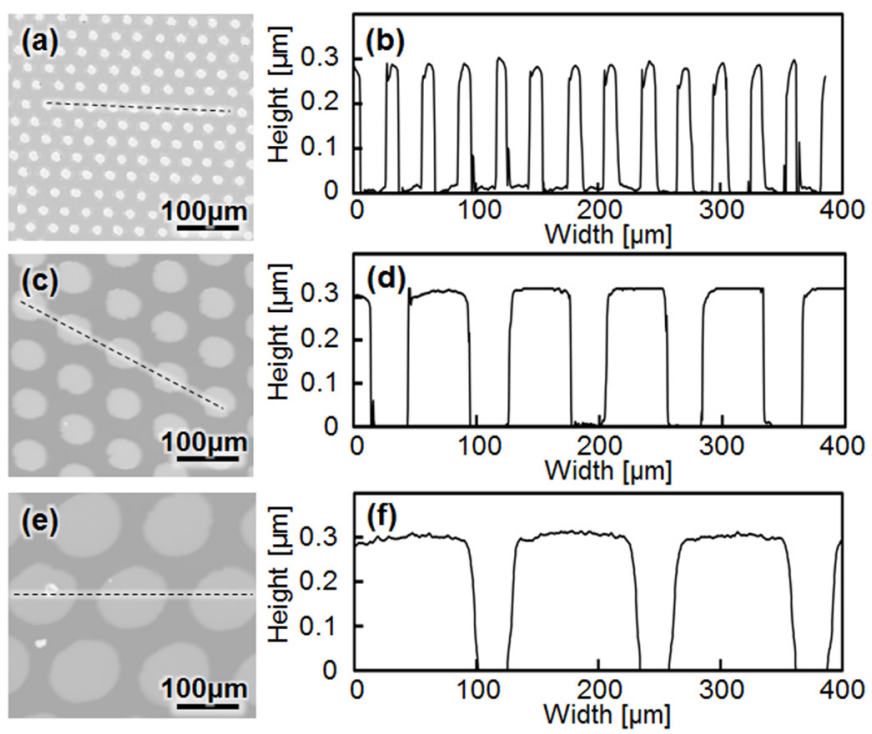

Fig. 3. Microscopic images of micro-textured DLC coatings and their surface profile with a texture diameter of $D=10 \mu \mathrm{m}(\mathrm{a}, \mathrm{b})$, $50 \mu \mathrm{m}(\mathrm{c}, \mathrm{d})$ and $100 \mu \mathrm{m}(\mathrm{e}, \mathrm{f})$ with a constant interspace of $l_{\text {inter }}=30 \mu \mathrm{m}$. Those dimensions are corresponding to the DLC coverage of 6,35 and $54 \%$, respectively.

manufacturing of masks, which can be used for patterned DLC-coating, is demonstrated. Based on these results, the systematic variation of the geometrical DLC parameters, diameter $D$, interspace distance $l_{\text {inter }}$ and coverage degree is ensured. The impact of these parameters on the tribological performance will be shown in detail in the following sections.

\subsection{Effect of diameter of micro-texture unit}

To study the effect of DLC pattern diameters on the tribological properties, the configurations shown in Figure 3 were used. At a constant interspace distance of $30 \mu \mathrm{m}$ the diameters amounted of 10,50 and $100 \mu \mathrm{m}$. Figure 5 shows the evolution of the coefficients of friction (COF) during 30000 laps of rotations in ball-on-disk friction tests. A continuous increase of COF from $\mu=0.15$ to 0.2 was observed for a texture diameter of $10 \mu \mathrm{m}$ until 10000 laps of rotation. In the following 20000 laps, the COF increase was accelerated to values up to 0.45 , whereby larger fluctuations (up to 0.8) were observed. In comparison, the texture diameters of 50 and $100 \mu \mathrm{m}$ led to lower and more stable COF. In average, $\mu$-values of 0.13 were obtained through the 30000 laps of rotation.

The optical images in Figure 6 show the wear tracks on the micro-textured DLC films as well as on the corresponding counterparts of SUJ2 balls after the 30000 laps of friction tests in dependence of the texture diameters. As can be seen in Figure $6 \mathrm{a}-\mathrm{c}$, the DLC coating was worn out after the 30000 laps of rotation for $D=10 \mu \mathrm{m}$, while this was not significantly affected for structure diameters of 50 and $100 \mu \mathrm{m}$. In addition, Figure $6 \mathrm{~d}-\mathrm{f}$ reveals that the largest diameter of worn area at the contact surface of the SUJ2 ball is also obtained for $D=10 \mu \mathrm{m}$. This can be explained by a larger stress concentration at the single
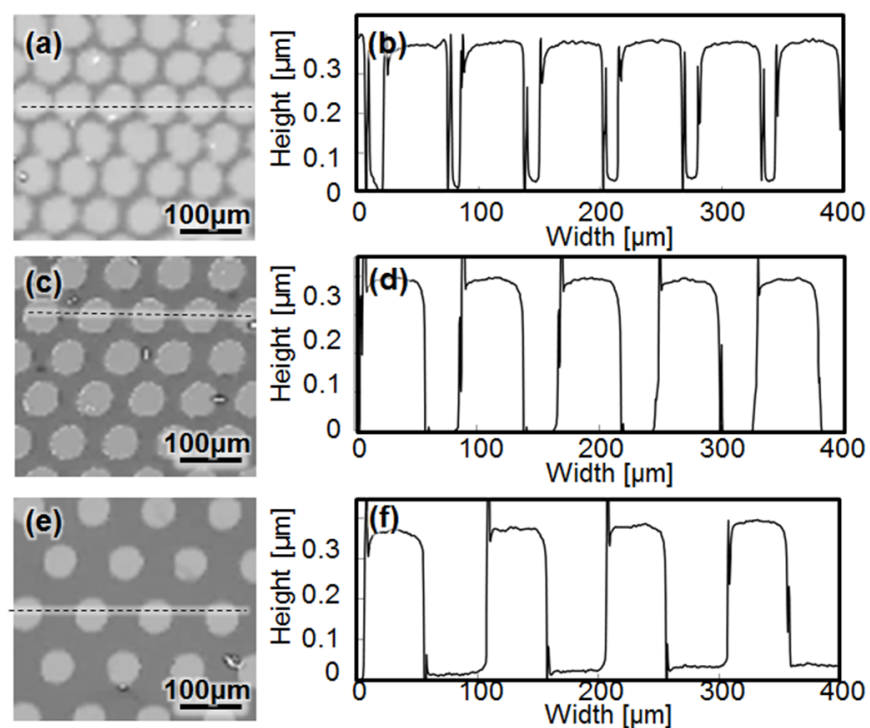

Fig. 4. Microscopic images of micro-textured DLC coatings and their surface profile with a texture interspace of $l_{\text {inter }}=15 \mu \mathrm{m}$ $(\mathrm{a}, \mathrm{b}), 30 \mu \mathrm{m}(\mathrm{c}, \mathrm{d})$ and $50 \mu \mathrm{m}(\mathrm{e}, \mathrm{f})$ with a constant diameter of $D=50 \mu \mathrm{m}$. Those dimensions are corresponding to the DLC coverage of 54,35 and $23 \%$, respectively.

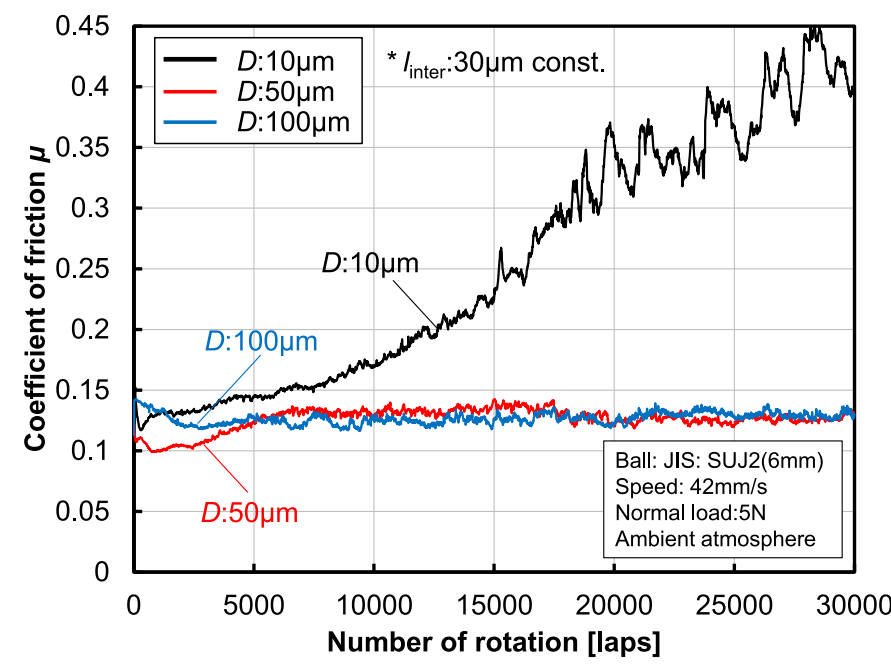

Fig. 5. Evolution of COF during ball-on-disk friction test of micro-textured DLC films with different texture diameters under constant interspace of $30 \mu \mathrm{m}$.

texture unit for smaller texture diameter, which can be expected by relatively low fraction of DLC coverage to the total area of $6 \%$ for $D=10 \mu \mathrm{m}$, while that of 35 and $54 \%$ for $D=50$ and $100 \mu \mathrm{m}$, respectively. An additional EDS analysis of the sliding surface of the ball counterpart, as depicted in Figure 7, shows that the tungsten (W) element was detected only for $D=10 \mu \mathrm{m}$. This indicates a direct contact of the SUJ2 balls with the WC-Co substrates and proves the wear of the DLC coating for the small diameter size.

Furthermore, a large amount of adhesion layer, denoted by arrows in Figure 6c, was observed at the worn area of the 

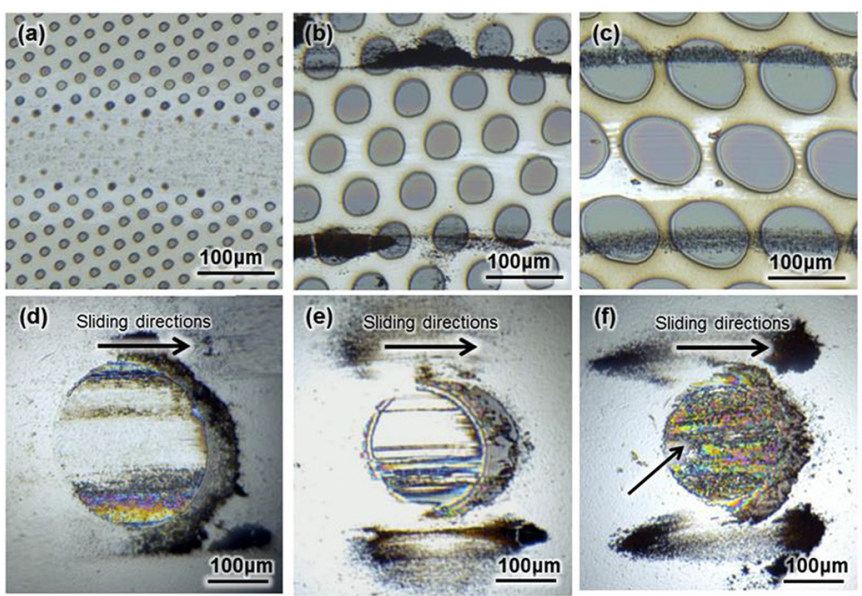

Fig. 6. Optical surface images of wear tracks of micro-textured DLC films with different texture diameters of $10 \mu \mathrm{m}$ (a), $50 \mu \mathrm{m}$ (b), and $100 \mu \mathrm{m}$ (c) as well as the corresponding counterparts of SUJ2 balls (d-f), respectively, after the 30000 laps of ball-on-disk friction tests.
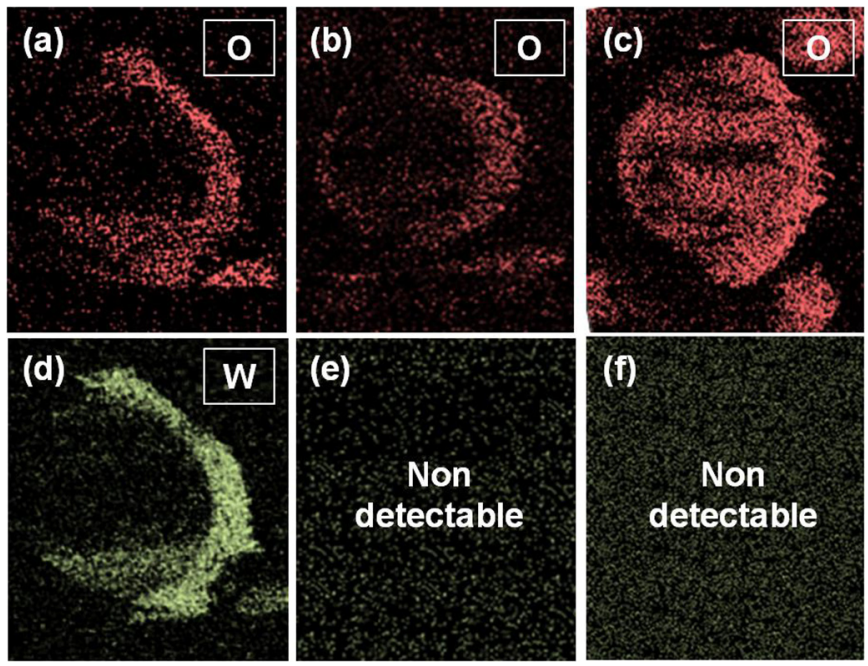

Fig. 7. EDS mapping images for the detection of oxygen $(\mathrm{O})$ at wear tracks of counterpart SUJ2 balls after BOD friction test with different texture diameters of $50 \mu \mathrm{m}$ (a), $100 \mu \mathrm{m}$ (b), and $150 \mu \mathrm{m}$ (c) as well as the detection for tungsten (W) (d-f), respectively.

ball surface for $D=100 \mu \mathrm{m}$. Whereas, this was not observed for $D=50 \mu \mathrm{m}$. The EDX analysis, depicted in Figure $7 \mathrm{c}$, indicates that this adhesion layer is related to oxide films, as a large amount of oxygen $(\mathrm{O})$ was detected. It is supposed that newly formed surface of the SUJ2 ball during the dry sliding friction rapidly reacts with the oxygen atmosphere and results in the formation of oxide films. In addition, wear debris generated from the contact interface can aggregate at the front side of sliding direction and thereby can also promote the formation of those oxide layers. These hard and brittle oxide films might plow the contacting pair or itself, which is well known as oxidative wear [9]. In fact, as can be seen from Figure 6c, the interspace between the DLC texture at the center of wear traces unit for $D=100 \mu \mathrm{m}$ was worn out following to the

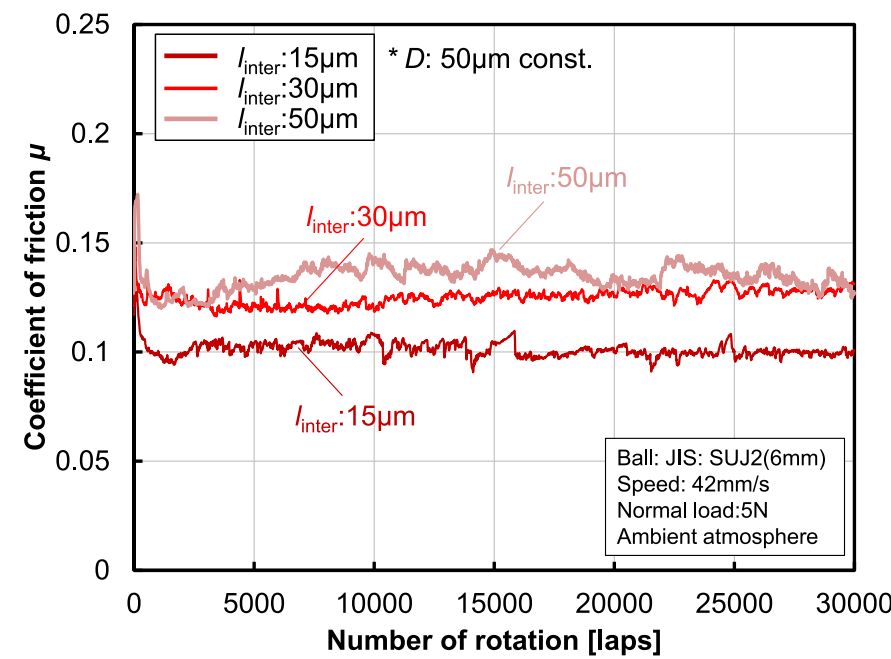

Fig. 8. Evolution of COF during ball-on-disk friction test of micro-textured DLC films with different texture interspace under constant texture diameter of $50 \mu \mathrm{m}$.

sliding direction. This could be attributed to the plowing by this hard oxide films formed at interface.

In comparison to the structure diameter of $100 \mu \mathrm{m}$, the ejection of the wear debris from the contact interface was more effective for $D=50 \mu \mathrm{m}$. This can be traced back to the smaller structure size, as previously observed in $[4,5]$. Therefore, the amount of wear debris at the front side of sliding directions could be less accumulated. This reduces thereby the tendency to form oxide layer. The comparison of the different diameters revealed that under the apparent contact pressure of $1.2 \mathrm{GPa}$, the texture diameter of $D=50 \mu \mathrm{m}$ led to the best tribological performance in view of the durability in wear and also for the stability owing to its effective ejection of wear debris.

\subsection{Effect of interspace between micro-texture units}

As a second geometrical quantity, the influence of the interspace distance on the tribological property of the patterned DLC coating was investigated. Thereby, $l_{\text {inter }}$ was varied from 15 to $50 \mu \mathrm{m}$, while the structure diameter was kept constant at $50 \mu \mathrm{m}$, as proved to ensure highest tribological performance (see Fig. 4). Figure 8 shows the evolutions of COF during 30000 laps of rotations in ballon-disk friction tests in dependence of the interspace distance. Thereby, it can be seen that a stable evolution is ensured through 30000 laps for all three interspaces. However, the lowest COF of $\mu=0.13$ was obtained for the smallest interspace of $l_{\text {inter }}=15 \mu \mathrm{m}$.

Moreover, Figure 9 summarizes the averaged COF obtained with all three interspace distances within the rotation lap ranging from 5000 to 25000 . Thereby, it is seen that the average COF increases linearly with the interspace $l_{\text {inter }}$ from $\mu=0.126 \pm 0.003$ to $\mu=0.162 \pm 0.004$.

To correlate the contact state during the friction tests with this linear dependency, the contact interface was recorded after the friction tests, see Figure 10. Especially, the images of SUJ2 ball counterparts show a clear influence of the interspace distance. The smallest worn area and 


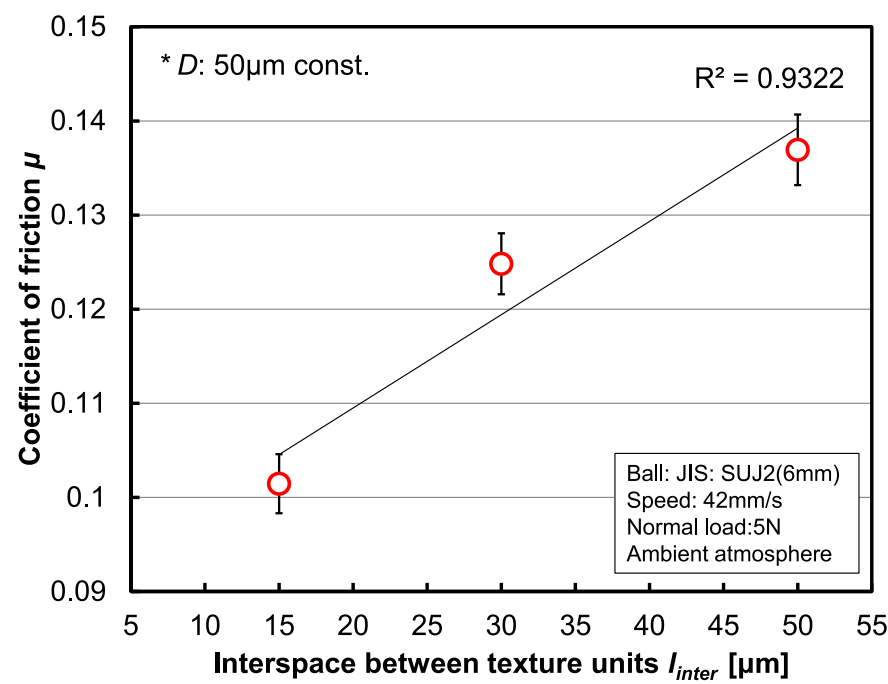

Fig. 9. Variations of averaged COF as a function of interspace between texture units of micro-textured DLC.
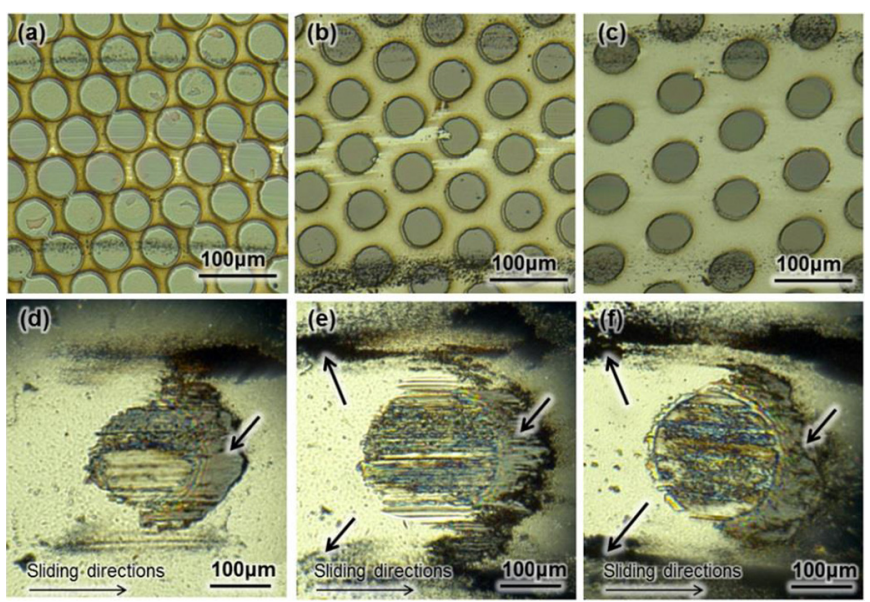

Fig. 10. Optical surface images of wear tracks of micro-textured DLC films with different texture interspace of $15 \mu \mathrm{m}$ (a), $30 \mu \mathrm{m}$ (b), $50 \mu \mathrm{m}$ (c) as well as the corresponding counterparts of SUJ2 balls $(\mathrm{d}-\mathrm{f})$, respectively, after the 30000 laps of ball-on-disk friction tests.

lowest amount of wear debris, which has accumulated at front and beside the sliding traces, were observed for the interspace $l_{\text {inter }}=15 \mu \mathrm{m}$. This explains the lowest COF for $l_{\text {inter }}=15 \mu \mathrm{m}$. According to the plowing component of $\mathrm{COF}, \mu_{\mathrm{p}}$, the real contact area of wear particles during the related plowing, $A_{\mathrm{p}}$, is apparently restricted by the number of included wear particles, $N_{\mathrm{tr}}$, as described by the following equation (1):

$$
\mu_{\mathrm{p}}=\frac{A_{\mathrm{p}} \tau_{\mathrm{p}}}{W_{\mathrm{N}}}=N_{\mathrm{tr}} \frac{\pi d_{\mathrm{p}}^{2}}{4} \cdot \frac{\tau_{\mathrm{p}}}{W_{\mathrm{N}}}
$$

where $d_{\mathrm{p}}$ is the average radius of wear particles, $\tau_{\mathrm{p}}$ is the shear stress to plow the surface and $W_{\mathrm{N}}$ is the applied normal load [2]. Thus, the reduction of the generated wear particles at the smaller interspace results in decreasing the plowing component and thereby leads to lower total COF, as shown in Figure 9.

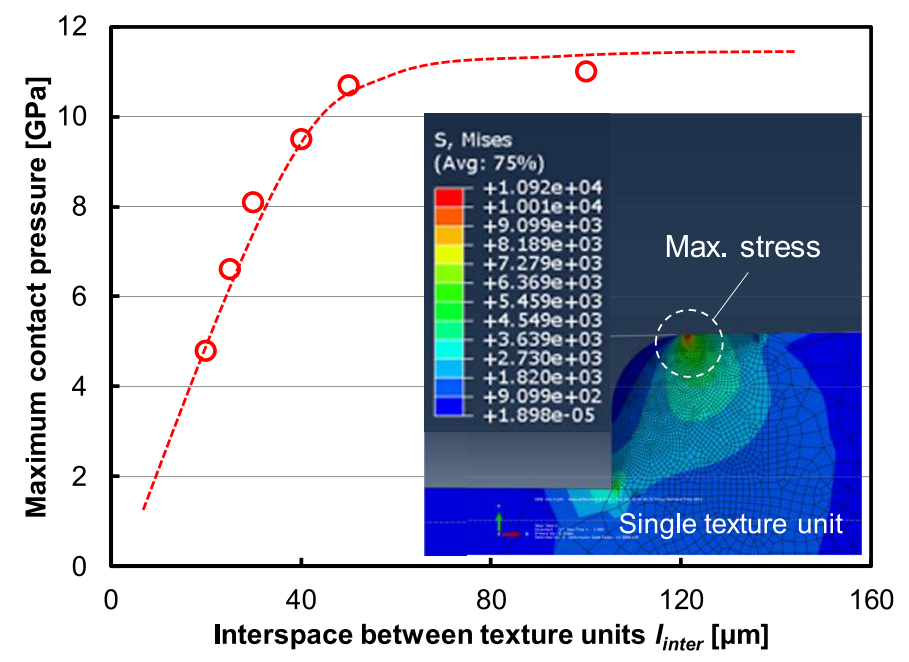

Fig. 11. Variation of maximum contact pressure as a function of interspace between texture units, obtained by FE simulation. Inset figure shows contour image of distribution of equivalent stress at DLC single unit.

One reason for the less amount of wear debris generation with $l_{\text {inter }}=15 \mu \mathrm{m}$ could be the lower local stress concentration at the contact interface, which can be expected also from the smaller diameter of worn area at ball surface. Figure 11 shows the maximum stress at a DLC structure as a function of the interspace between DLC islands, calculated by finite element analysis. The calculation conditions are available in Appendix A. By decreasing the interspace, the maximum stress at the edge of the DLC structure decreases. This could explain the less amount of wear of both DLC structure and ball surface with $l_{\text {inter }}=15 \mu \mathrm{m}$. In parallel, the decrease in the interspace resulted in more and more distribution of the concentrated stress at the edge corner to the neighboring structure. This could also explain the less DLC wear with $l_{\text {inter }}=15 \mu \mathrm{m}$. Additional EDS analysis shown in Figure 12 also supports this statement, as $\mathrm{W}$ was only detected for the largest interspace of $l_{\text {inter }}=50 \mu \mathrm{m}$. It suggests that this direct contact with WC-Co substrate is related to a higher stress concentration and promotes the wear debris generation. This will be then reflected in increasing the plowing component of COF. Consequently, it can be stated that the effect of interspace distance on the tribological performance of the DLC patterns is strongly related to stress concentration at the edges of the single DLC islands.

\subsection{Wear durability under constant DLC coverage}

Durability on wear of micro-textured DLC films was investigated by longer run of rotation of 100000 laps. Here, alumina balls were used to eliminate the effect of wear of ball itself. To evaluate the effect of texture diameter under the same apparent contact pressure, following three geometrical conditions were chosen to keep a constant ratio of the DLC-coverage in unit area (40\%); $D=50 \mu \mathrm{m}$ with $l_{\text {inter }}=25 \mu \mathrm{m}, D=100 \mu \mathrm{m}$ with $l_{\text {inter }}=50 \mu \mathrm{m}$ and $D=150 \mu \mathrm{m}$ with $l_{\text {inter }}=75 \mu \mathrm{m}$. The optical images of the 

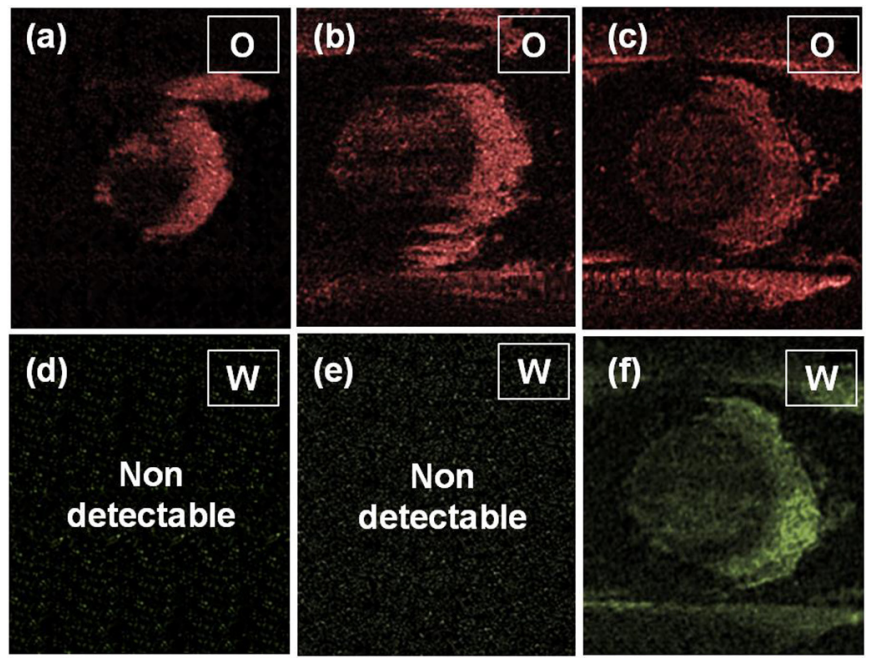

Fig. 12. EDS mapping images for the detection of oxygen $(\mathrm{O})$ at wear tracks of counterpart SUJ2 balls after BOD friction test different texture interspace of $15 \mu \mathrm{m}$ (a), $30 \mu \mathrm{m}$ (b), and $50 \mu \mathrm{m}$ (c) as well as the detection for tungsten (W) $(d-f)$, respectively.
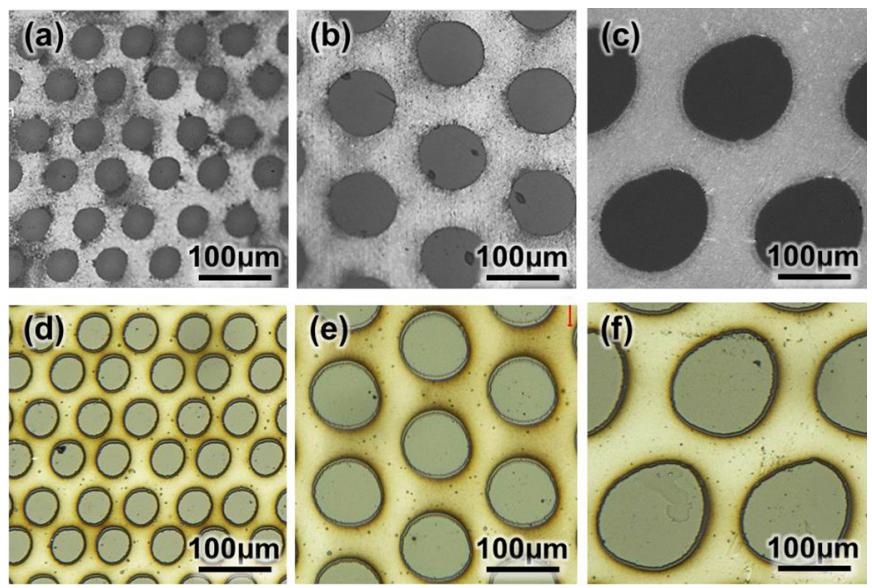

Fig. 13. Optical microscopic images of the laser processed metallic masks with different diameter $D$ of $50 \mu \mathrm{m}$ (a), $100 \mu \mathrm{m}$ (b) and $150 \mu \mathrm{m}(\mathrm{c})$ with a constant DLC coverage and that of the corresponding micro-textured DLC $(\mathrm{d}-\mathrm{f})$.

laser machined metallic masks and the corresponding micro-textured DLC are shown in Figure 13.

Figure 14 shows the evolution of the coefficient of friction (COF) during (a) 10000 laps and (b) 100000 laps of rotations in ball-on-disk friction tests for both, nontextured and micro-textured DLC films. As can be expected from the previous study, a high COF with relatively large deviation is shown for the non-textured films. In contrast, the use of textured DLC shows a significant influence of the texture diameter on the resulting $\mathrm{COF}$ in the first 5000 laps of rotation. In particular, the texture with the smallest diameter of $50 \mu \mathrm{m}$ shows a relatively low COF value of $\mu=0.09$ with almost no deviations from the initial rotation, which has the good agreement with the obtained results in the previous section for SUJ2 balls. This stability with smaller diameter is assumed to be due to the suppression of plowing by the

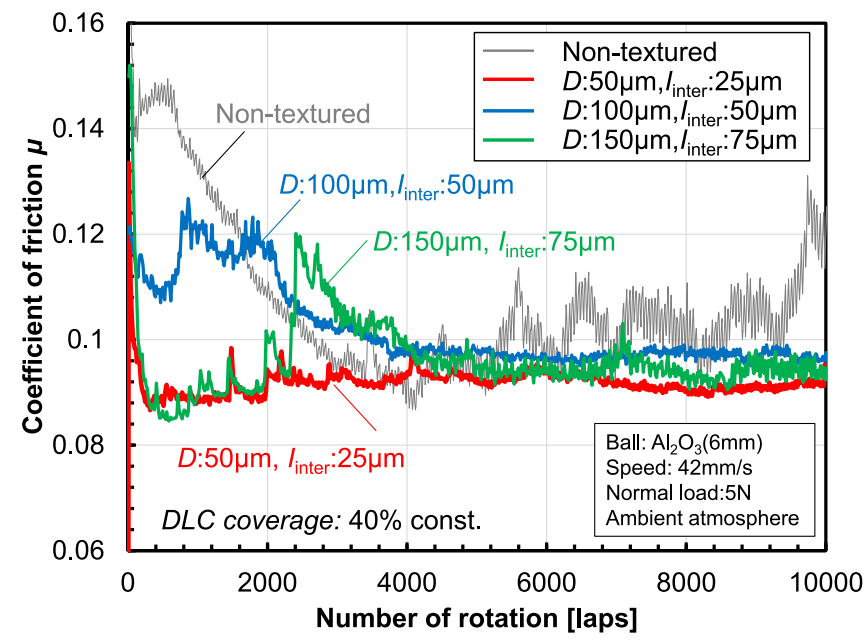

(a)

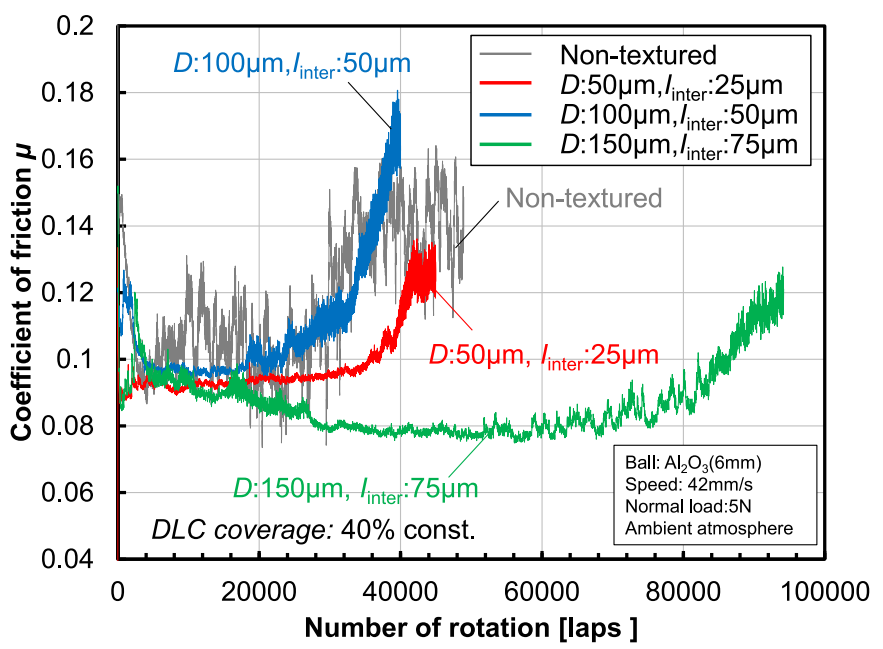

(b)

Fig. 14. Evolution of COF during (a) initial 10000 laps and (b) until 100000 laps of ball-on-disk friction test of non-textured and micro-textured DLC films with different texture dimensions.

wear debris at contact interface [3]. Taking into account the scale effect of the three-body deformation, the real area of contact of three-body plowing is approximately $1 / 6$ at the original scale dimensions by scaling down the apparent contact area to the half [10]. Thus, the entrapment probability of wear debris at the interface decreases and thereby contributes to the stable and lower friction under dry sliding conditions.

Above 10000 laps, however, the micro-textured DLC with smallest texture diameter of $50 \mu \mathrm{m}$ shows a limited durability compared to that obtained with the largest texture diameter of $150 \mu \mathrm{m}$, see Figure 14b. After approximately 40000 laps of rotation, the COF of the texture diameter of $50 \mu \mathrm{m}$ increases significantly, while the texture patterns with diameter of $150 \mu \mathrm{m}$ reveal more than twice longer durability up to $>80000$ laps. Thereby, the COF level is maintained constant around $\mu=0.08$. In comparison, the durability of the $100 \mu \mathrm{m}$ wide DLC pattern was even worse. The COF began to increase already after only 20000 laps. 


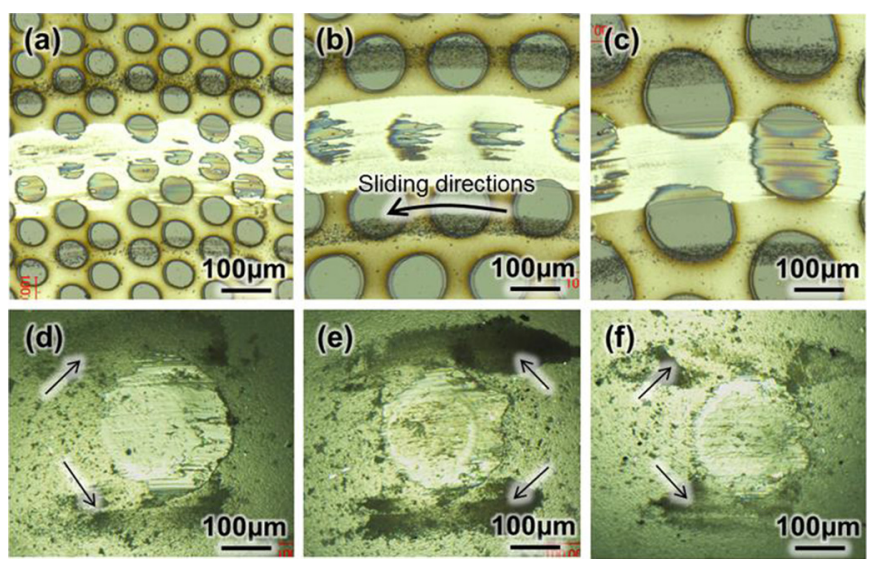

Fig. 15. Optical surface images of wear tracks of micro-textured DLC films with different texture diameters of $50 \mu \mathrm{m}$ (a), $100 \mu \mathrm{m}$ (b), $150 \mu \mathrm{m}$ (c) as well as the corresponding counterparts of alumina balls $(\mathrm{d}-\mathrm{f})$, respectively, after the ball-on-disk friction tests.

As can be seen in Figure 15a-c, the DLC coating on the patterns with the largest diameters $(D=150 \mu \mathrm{m})$ remained even after the 90000 laps of rotation, while the DLC layer was almost worn after 40000 laps of rotation on the pattern with smaller diameters of 50 and $100 \mu \mathrm{m}$. In fact, the wear debris, including large amount of carbon was accumulated beside the sliding tracks for the textured diameter of 50 and $100 \mu \mathrm{m}$, which shows the wear of the textured DLC structure even under the same coverage of DLC films at unit area. According to the classical empirical equation of wear volume proposed by Archard [11], those higher wear rates in smaller textured structure seem to be attributed to the higher local surface pressure for the smaller diameters during the sliding of the spherical surface of the ball. According to the FE analysis shown in Figure 11, the stress concentration seems to be high at the edge of the texture during the sliding and thereby it promotes the wear of the DLC structure. This can be clearly seen in Figure $15 \mathrm{~b}$, in which the right edge of the DLC islands is preferentially worn. In parallel, Figure 15e shows that the sliding direction determines the stress concentration of the ball.

In addition, the comparison between Figures 15d and $15 \mathrm{e}$ indicates that the accumulation of carbon wear debris beside the worn spots at the alumina balls is less for textured diameter of $50 \mu \mathrm{m}$ than that of $100 \mu \mathrm{m}$. This is well corresponding to the results shown in Figure 6, which could be attributed to the effective ejection of wear debris by the scale effects of three-body plowing and might contribute to the slightly higher durability for the DLC pattern with a diameter of $50 \mu \mathrm{m}$. Moreover, Figure $15 \mathrm{f}$ shows a low amount of accumulated carbon particles for the texture diameter of $150 \mu \mathrm{m}$, which explain also the longer durability of these structures.

To fulfill the requirements of a stable and durable dry sliding, the efficient ejection of wear debris from contact interface, the suppression of wear debris generation, and the decrease of stress concentration represent the key parameters for a suitable texture design of the DLC pattern. In particular, by scaling down of the apparent contact area of texture unit, although the efficient ejection of wear debris can be expected, the stress concentration will be higher. Thus, the control of interspace will be an effective approach to distribute the stress concentration and minimize the generation of wear debris to improve the durability of DLC structure.

\section{Conclusions}

Through the tribological evaluation of ball-on-disk type friction tests under different geometrical conditions of micro-textured DLC patterns, following conclusions can be drawn:

- Under the Hertzian mean contact pressure of $1.2 \mathrm{GPa}$ and elastic contact diameter of approximately $110 \mu \mathrm{m}$ and a constant interspace of $l_{\text {inter }}=30 \mu \mathrm{m}$, the best tribological performance during the 30000 laps of rotation between different texture diameters was demonstrated at the diameter of $D=50 \mu \mathrm{m}$.

- The COF decreases with decreasing $l_{\text {inter }}$. During the 30000 laps of rotation, the lowest COF of $\mu=0.13$ was obtained at $l_{\text {inter }}=15 \mu \mathrm{m}$, owing to the distributed stress concentration by the neighboring texture units, which contributed to the less generation of wear debris.

- Larger DLC structure $(D=150 \mu \mathrm{m})$ showed more than twice longer durability than that of smaller diameter. This lower wear resistivity with smaller diameters is attributed to the local high stress concentration at the edge of the single texture units.

In summary, stable and reduced friction under dry sliding condition can be achieved by balancing the apparent contact area of textured unit and its ratio to the interspace, considering the efficient ejection of wear debris from contact interface and the stress concentration on the DLC structure. Future works will focus on quantitative structural analysis in order to design appropriate geometrical structures and dimensions for the favorable contact state in metal forming process.

\subsection{Implications and influences}

The present study clarified the importance of the diameters and interspace of micro-textured DLC unit on its tribological performance. In particular, the efficient ejection of wear debris from interface and the stress concentration at DLC structure has a great impact on coefficient of friction and the wear resistivity. This may contribute to optimize the geometrical design of microtextured surface for the realization of stable and durable friction under dry sliding conditions towards the realization lubricant-free forming process.

The authors gratefully thank the financial support from Tokyo Metropolitan University in the framework of the CoTutorial Program in 2016 as well as from the minister for science, health and consumer protection of the free hanseatic city Bremen. 


\section{Appendix A}
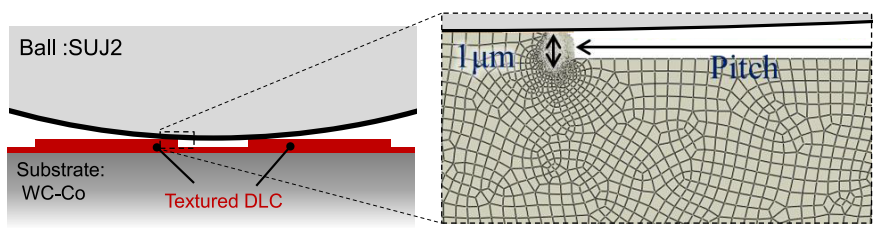

Fig. A.1. Schematic illustration of the FE model of ball on disk friction test.

To calculate the stress distribution at the single texture unit, finite element analysis was performed by modeling the contact state of ball on disk friction test as shown in Figure A.1. The simulation was carried out with a finite element code, Abaqus version 6.13. Two-dimensional shell element (element type: CPS4R) with a size of $50 \mathrm{~nm} \times 50 \mathrm{~nm}$ was used. The model of DLC texture unit was assumed to be isotropic elastic body, and the counterpart ball was assumed to be rigid body. Table A.1 shows the mechanical properties of the DLC texture unit used in the simulation. The contact between the DLC texture unit and ball was analyzed by using penalty method and its friction coefficients were assumed to be 0.1 , based on the result of friction test with a non-texture DLC. Maximum equivalent stress of DLC texture unit under the load of $5 \mathrm{~N}$ at the ball was calculated between the different interspace distance of $l_{\text {inter }} 25,40,50$, $80,100 \mu \mathrm{m}$.
Table A.1. Mechanical properties of DLC texture unit.

\begin{tabular}{lll}
\hline Material model & $\begin{array}{l}\text { Young's } \\
\text { modulus } E(\mathrm{GPa})\end{array}$ & Poisson's ratio \\
\hline Elastic body & 250 & 0.3 \\
\hline
\end{tabular}

\section{References}

1. N. Bay, A. Azushima, P. Groche, I. Ishibashi, M. Merklein, M. Morishita, T. Nakamura, S. Schmid, M. Yoshida, CIRP Ann. 59 (2010) 760-780

2. B. Bhushan, Introduction to tribology, 2nd edn. John Wiley \& Sons, New York, 2013

3. N.P. Suh, H.C. Sin, Wear 69 (1981) 91-114

4. B. Bhushan, M. Nosonovsky, Acta Mater. 52 (2004) 2461-2474

5. M. Nosonovsky, B. Bhushan, ASME J. Tribol. 127 (2005) $37-46$

6. T. Shimizu, T. Kakegawa, M. Yang, Procedia Eng. 81 (2014) 1884-1889

7. T. Kakegawa, T. Shimizu, M. Yang, J. Jpn. Soc. Technol. Plast. 56-657 (2015) 891-896

8. J. Meijer, K. Du, A. Gillner, D. Hoffmann, V.S. Kovalenko, T. Masuzawa, A. Ostendorf, R. Poprawe, W. Schulz, CIRP Ann. 51 (2002) 531-550

9. T.F.J. Quinn, J.L. Sullivan, D.M. Rowson, Tribol. Int. 13 (1980) $153-158$

10. T. Shimizu, M. Yang, K. Manabe, Wear 330-331 (2015) 49-58

11. E. Rabinowicz, Friction and wear of materials, John Wiley \& Sons, New York, 1995

Cite this article as: Tetsuhide Shimizu, Hironori Kan, Hamza Messaoudi, Frank Vollertsen, Ming Yang, Impact of geometrical parameters of micro-textured DLC on tribological properties under dry sliding friction, Manufacturing Rev. 6, 18 (2019) 